\title{
Estudio de la osteología radiográfica de la rana pipa (Pipa pipa)
}

\author{
Study Of The RAdIOGRAPHic OSTEOLOGY OF THE PIPA FROG (Pipa pipa) \\ Ricardo Grandez R. ${ }^{1,2}$, Melina Raffael A. ${ }^{1}$, Catalina Hermoza G. ${ }^{1}$, \\ Roberto Valencia L. ${ }^{1(\dagger)}$
}

\section{Resumen}

Para el estudio de la osteología radiográfica de la rana Pipa pipa se emplearon seis especímenes adultos mantenidos en cautiverio, en aparente buen estado de salud. Se utilizó el equipo de Rayos X MinXray® HF 100 para obtener las imágenes radiográficas y se describió las características radiográficas y dimensiones (largo y ancho) de la cabeza, esqueleto pos-craneal, cintura escapular, miembros anteriores y posteriores. Se determinó que presentan las vértebras pre-sacrales I y II fusionadas, y el sacro fusionado al delgado urostilo. La cintura escapular de Pipa pipa es pseudo-firmisternal, lográndose identificar los huesos que conforman esta región, incluido el coracoides. La relación entre las medidas del largo de la tibia-fíbula sumado al largo del pie con el largo corporal correspondió al $85 \%$.

Palabras clave: rana; Pipa pipa; osteología; radiología

\section{Abstract}

For the study of the radiographic osteology of the Pipa pipe frog, six adult specimens apparently in good health and kept in captivity were used. The MinXray ${ }^{\circledR}$ HF 100 X-ray equipment was used to obtain the radiographic images, analyze the radiographic characteristics and determine the size (length and width) of the head, post-cranial skeleton, shoulder girdle, anterior and posterior limbs. These frogs present the pre-sacral vertebrae I and II fused, and the sacrum fused to the thin urostil. Pipa pipe scapular waist is

\footnotetext{
${ }^{1}$ Departamento de Medicina Veterinaria y Zootecnia, Facultad de Medicina Veterinaria y Zootecnia, Universidad Peruana Cayetano Heredia, Lima, Perú

${ }^{2}$ E-mail: rgrandez@hotmail.com
}

Recibido: 14 de agosto de 2017

Aceptado para publicación: 31 de diciembre de 2017 
pseudo-firmisternal. It was possible to identify the bones that make up this region, including the coracoides. The relation between the measures of the tibial-fibula length added to the length of the foot with the corporal length corresponded to $85 \%$.

Key words: frog; Pipa pipa; ostheology; radiology

\section{INTRODUCCIÓN}

El orden Anura representa el grupo más grande de diversidad de anfibios con un número de 7304 especies divididas en 54 familias (AmphibiaWeb, s.f.). La rana pipa pertenece a la Familia Pipidae, género Pipa. Las especies de este género son acuáticas, no tienen párpados ni lengua retráctil y poseen papilas gustativas en la punta de los dedos de los miembros traseros (Fowler y Cubas 2001).

P. pipa es nativa del Perú y de otros países del noreste de sudamérica: Colombia, Bolivia, Brasil, Ecuador, Guayana Francesa y Venezuela (IUCN, 2015). La familia Pipidae presenta particularidades reproductivas, como cientos de huevos fertilizados y depositados sobre la espalda de las hembras que son gradualmente absorbidos por el tejido cutáneo durante los 60 días de incubación (Fowler, 2001). A diferencia de otras especies, han comprimido excepcionalmente sus cuerpos con cabezas anchas, planas y triangulares, donde $P$. pipa es la más larga de las siete especies, llegando a medir hasta más de 171 mm de longitud corporal (Trueb et al., 2000).

El examen radiológico es una prueba imagenológica no invasiva, útil para estudiar las estructuras internas de los organismos vivos (Lannoo, 2008). La técnica radiológica es importante en el diagnóstico de algunas enfermedades de los anfibios y particularmente útil en el diagnóstico de desórdenes del esqueleto óseo, cálculos en el tracto urinario, mineralización de tejidos, enfermedades pulmonares y cuerpos extraños en el sistema gastrointestinal (Scherff-Norris et al., 2002).
Por lo general, a menos que alguna anormalidad esté presente, no es posible diferenciar las estructuras en cavidad celómica en la radiografía de anfibios (Ballard y Cheek, 2003).

La descripción anatómica de la osteología craneal y pos-craneal de los anfibios requiere posicionar al espécimen en vistas dorsoventral y lateral (Ballard y Cheek, 2003). Estudios realizados a partir de esqueletos Pipa sp indican que el cráneo es aproximadamente 1.5 veces más ancho que largo y extremadamente deprimido, lo cual es atípico en relación a otras especies de ranas. La arcada maxilar carece de dientes y de una cresta dental. El hueso frontoparietal es grande y profundo, dorsalmente cóncavo, y presenta crestas supraorbitales. El hueso pterigoides es robusto y sostiene la mayor parte de la órbita anterior. El hueso escuamosal está unido con el anillo timpánico para formar una estructura en forma de concha denominada hueso timpanoescuamosal (Trueb y Cannatela, 1986).

En anuros, la cápsula nasal y el esfenetmoides se origina en un solo bloque de cartílago. El septo nasal puede estar variablemente osificado como el tactum (techo) y el solum (piso nasal). Los nasales son elementos triangulares amplios. El cartílago de Meckel está expuesto en la región sinfisial y es la continuación de ambas mandíbulas. La mandíbula carece de articulación entre sus mitades. La gran septomaxila es cerca a la cuarta parte del largo de la maxila. Los huesos vómer y neopalatinos (algunos autores los llaman palatinos), cuadradoyugal, y los huesos mentomeckelianos están ausentes (Báez y Trueb, 1997). 
En la mayoría de anuros, el cráneo endocraneal es completo excepto por las fontanelas dorsales (por ejemplo, la fontanela frontoparietal o frontal y una o dos fontanelas parietales) y está compuesto por un par de cartílagos esfenetmoides, proóticos y exoccipitales; cada uno de los cuales contribuye a la capsula ótica. Dorsalmente, la porción posterior del frontoparietal se superpone al proótico. Los huesos exoccipitalis forman las paredes posteromediales de la capsula ótica, el margen del foramen magnun y los cóndilos occipitalis (Trueb et al., 2000).

La columna vertebral está compuesta por ocho vértebras presacrales opistocélicas, el sacro y el urostilo, y todas las vértebras están completamente imbricadas. La primera y segunda vértebra están imbricadas y fusionadas, en tanto que el delgado urostilo está fusionado con el sacro (Baez y Trueb, 1997).

La cintura escapular de la $P$. pipa es pseudofirmisternal; el esternón es un plato largo, cuadrilátero, de cartílagos superpuestos y está conectado a la parte posterolateral de los cartílagos epicoracoides. Unas pequeñas áreas de calcificación se encuentran en estos cartílagos, entre los extremos esternales de los coracoides. Los ejes longitudinales de la robusta clavícula son rectos y orientados en casi un ángulo de $45^{\circ}$ a la línea media del cuerpo. La escápula es pequeña y está modestamente desarrollada en contraste con la clavícula y el coracoides. Medialmente, la escápula forma la pared dorsolateral de la fosa glenoide, cuya porción anterodorsal está compuesta por un plato cóncavo grueso ( $p a r$ acromalis), mientras que la parte posterodorsal (par glenoidalis) está representada por una concavidad en el extremo proximal de la escápula. El cartílago supraescapular se extiende distalmente como una hoja ancha y plana (Trueb y Massemin, 2000).

Los miembros delanteros están conformados por un húmero largo, con una bien desarrollada, pero corta, cresta ventral proximal. La cabeza distal (eminentia capitata) está osificada, la cabeza glenoide (cabeza de húmero) se expande y tiene forma de cuña. El radio-ulna es de característica aplanada (Trueb et al., 2000), y la mano consta de 8 elementos carpales, 4 metacarpos y 10 falanges, con una fórmula falangeal de 3-3-2-2 (Trueb, 1984).

La cintura pélvica está compuesta por el ilion, isquion y un pubis fusionado, que unidos forman el acetábulo oval. Las márgenes internas de los huesos ilíacos forman una «U» (Báez et al., 2008). Las extremidades posteriores y pies están conformados por el fémur que es relativamente largo y débilmente sigmoideo. La tibia-fíbula es delgada y corta en comparación del fémur; además el pie posee un calcáneo y astrágalo o también llamado tibial-fibular, respectivamente (Trueb, Púgener y Maglia, 2000); 5 metatarsos y 14 falanges, con una fórmula falangeal de 2-23-4-3 (Trueb, 1984).

El objetivo del presente estudio fue describir las características y dimensiones de la osteología radiográfica de la cabeza, esqueleto pos-craneal, cintura escapular, y miembros anteriores y posteriores de la rana Pipa (Pipa pipa).

\section{Materiales y Métodos}

El estudio radiográfico se realizó en el Parque Zoológico de Huachipa (PZH), Consorcio Ecolatina S.A.C., ubicado en el distrito de Ate Vitarte, Lima, Perú. El trabajo correspondió a un estudio de tipo descriptivo que permitió determinar las características anatómicas del esqueleto óseo de animales de la especie Pipa pipa.

El tamaño de muestra correspondió a seis ejemplares, sin definición de género, de la colección del PZH, en aparente buen estado de salud, sin tratamientos o enfermedades en los tres meses previos al estudio. Para corroborar el buen estado de salud se realizó el examen clínico general por un Médico Ve- 
terinario del PZH, el cual se basó en la inspección del ambiente, grado de alerta, color, posición en el agua y postura, frecuencia respiratoria antes de la sujeción, chequeo de la cavidad oral, extremidades y piel, según el protocolo descrito por Miller y Fowler (2012).

Para las tomas radiográficas se utilizó el equipo de rayos X MinXray ${ }^{\circledR}$ HF 100 de propiedad de $\mathrm{PZH}$ y placas radiográficas de acetato Kodak ${ }^{\circledR}$ Medical X-Ray Film General Purpose Green de 27.9x35.6 cm. Los animales fueron pesados y luego posicionados mediante técnicas de manejo convencional sobre el chasis del equipo en posición dorsoventral y posición lateral.

Los valores de exposición utilizados fueron: posición dorsoventral $44 \mathrm{Kv}, 20 \mathrm{~mA}, 0.01 \mathrm{~s}$ y posición lateral $60 \mathrm{Kv}, 20 \mathrm{~mA}, 0.04 \mathrm{~s}$, siguiendo el protocolo de valores de exposición radiográfica del $\mathrm{PZH}$. El revelado se realizó convencionalmente en cuarto oscuro utilizando líquido de revelado $\operatorname{Kodak}^{\circledR}$ GBX y luego sumergidas en el reactivo fijador Kodak $^{\circledR}$ GBX por 2 minutos. Las placas fueron secadas al ambiente y revisadas con el uso del negatoscopio convencional (Ver figuras 1 al 5). Las imágenes radiográficas fueron documentadas mediante técnica fotográfica digital. En las radiografías se realizaron las siguientes mediciones: largo corporal, ancho y largo del cráneo, así como las dimensiones de los huesos húmero, radio-ulna, fémur, tibio-fíbula, calcáneo, astrágalo y sacro. Se determinaron los componentes óseos de la mano y pie, y se determinó el número de vértebras de la columna vertebral.

Las mediciones se realizaron usando la vista dorsoventral de la placa radiográfica y consideraron los siguientes puntos anatómicos:

- Largo del cráneo: distancia desde el cartílago nasal hasta la cresta externa del cóndilo occipital.

- Ancho del cráneo: distancia desde el punto externo máximo del hueso timpanoesquamosal izquierdo hasta el punto exter- no máximo del timpanoesquamosal derecho.

- Largo del húmero: distancia del borde proximal de la cabeza glenoide (caputhumeri) al borde de la cabeza distal (eminentiacapitata) del mismo.

- Ancho del húmero: en el punto medio de la diáfisis del humeral.

- Largo de la radio-ulna: distancia del borde proximal del olecranon al extremo más distal del hueso.

- Ancho de la radio-ulna: correspondió al punto medio de la diáfisis del mismo.

- Largo del fémur: distancia entre el borde de la cabeza proximal del fémur (caputfemoralis) hasta la cabeza distal del cóndilo lateral.

- Ancho del fémur: en el punto medio de la diáfisis del fémur.

- Largo de la tibio-fíbula: distancia entre el borde proximal del cóndilo lateral hasta la cabeza distal del mismo.

- Ancho de la tibio-fíbula: en el punto medio de la diáfisis del mismo.

- Huesos calcáneo y astrágalo: se midió la longitud del extremo proximal al distal.

- Largo de la pelvis: distancia del borde proximal del ilion a la parte distal del isquion.

- Ancho de la pelvis: distancia entre la dorsal del ilion hasta el lado opuesto medial del mismo.

La vista lateral de los especímenes no aportó información adicional en la descripción de la osteología de los especímenes debido a la sobreposición de los componentes óseos por la forma aplanada ventrodorsal de la especie.

Se obtuvieron los promedios como medida de tendencia central y el desvío estándar como medida de dispersión en cada una de las variables cuantificadas. Asimismo, se realizó un esquema a partir de las imágenes radiográficas para describir la anatomía radiográfica de la especie. 


\section{Resultados}

Los seis especímenes fueron clasificados como adultos de acuerdo con lo descrito por Trueb et al. (2000). Los animales tuvieron un promedio de $263.3 \pm 109.1 \mathrm{~g}$ de peso vivo (Cuadro 1). Las medidas del cráneo, y de los huesos húmero, radio-ulna, fémur, tibio-fíbula, calcáneo, astrágalo, sacro, pelvis, así como la longitud total del esqueleto y el número de vértebras se muestran en los cuadros 1 y 2 .

La relación entre las medidas del largo de la tibio-fíbula sumado al largo del pie (hueso calcáneo, astrágalo, metatarsos y falanges) correspondió al $84.1 \%$ del largo corporal (Cuadro 3). El número de falanges observadas en el miembro anterior fue: dedo II, 2 falanges; dedo III, 2 falanges; dedo IV, 3 falanges; y dedo V, 3 falanges. En el miembro posterior fue: dedo I, 2 falanges; dedo II, 2 falanges; dedo III, 3 falanges; dedo IV, 3 falanges; y dedo V, 3 falanges (Figuras 4 y 5 ).

A partir de las imágenes radiográficas se elaboraron esquemas de la anatomía radiológica de la rana P. pipa (ver Figuras 1, 2, 3, 4 y 5). En estos esquemas se puede observar que las vértebras pre-sacrales I y II están fusionadas, al igual que el sacro al delgado urostilo. La cintura escapular de la Pipa pipa se observó masiva, con clavículas fuertemente arqueadas y con una escápula corta.

Un hallazgo de interés fue una estructura alargada de radiopacidad intermedia ubicada entre la $3^{\text {ra }}$ y $5^{\text {ta }}$ vertebra en 4 de los 6 especímenes estudiados (Figura 3).

\section{Discusión}

La anatomía aplanada dorsoventralmente de esta especie podría aludirse a varias razones de adaptación, como por ejemplo, llevar sus huevos en la espalda y el camuflaje que asemeja a una roca en el fon- do de los ríos de aguas negras, con fondos cubiertos de vegetación y fango en el que habitan, lo cual permite que sus presas se confundan y se acerquen para ser succionadas por su cavidad oral. Se ha demostrado en esta especie, además, que emplea sus miembros anteriores a manera de cucharas para la captura de sus presas (MINAM-AECID, 2009; Carreño y Nishikawa, 2010; AMNH, s.f.).

Una adaptación biomecánica a su medio ambiente lo constituyen la ubicación en los batracios arciferales de los cartílagos epicoracoides sobrepuestos y los pectorales firmisternales de los cartílagos epicoracoides fusionados a lo largo de la línea media, constituyendo una sola plataforma. Experimentos cinematográficos en anuros que saltan muestran que los cartílagos epicoracoides de los pectorales arciferales se mueven uno sobre el otro al tiempo de salir a tierra, siendo diferente al de los arciferales (Emerson 1983; Borkhvardt y Ivashintsova, 1994). En el caso de los anuros firmisternales, por su esternón y sacros fusionados, están diseñados para absorber el golpe al momento de salir a tierra sin mover sus miembros durante la locomoción, lo que sugiere que hay aspectos morfológicos que diferencian a estas especies que deben ser analizados desde el punto de vista biomecánicos y en el ambiente donde viven (Emerson 1983; Borkhvardt y Ivashintsova, 1994).

La cintura escapular de $P$. pipa es pseudo-fimirsternal, típico en las ranas de esta familia (Trueb y Massemin, 2000), lográndose en este estudio identificar con precisión los huesos que conforman esta región, observándose con nitidez el coracoides. Los anuros firmisternales denotan una morfología pectoral de los anuros, donde el cartílago epicoracoides está unido o fusionado anterior y posteriormente; $y$ usualmente tienen un omosternum, lo cual contrasta con la otra morfología predominante que es la arciferal (Kaplan 1993; Borkhvardt y Ivashintsova, 1994). 
Cuadro 1. Peso vivo y medidas de largo y ancho del cráneo, húmero, radio-ulna, fémur, tibio-fíbula de seis especímenes de la especie Pipa pipa del Parque Zoológico de Huachipa, Lima, determinadas mediante examen radiológico

\begin{tabular}{cccccccccccc}
\hline Rana & $\begin{array}{c}\text { Peso } \\
(\mathrm{g})\end{array}$ & \multicolumn{2}{c}{$\begin{array}{c}\text { Cráneo } \\
(\mathrm{mm})\end{array}$} & \multicolumn{2}{c}{$\begin{array}{c}\text { Húmero } \\
(\mathrm{mm})\end{array}$} & \multicolumn{2}{c}{$\begin{array}{c}\text { Radio-ulna } \\
(\mathrm{mm})\end{array}$} & \multicolumn{2}{c}{$\begin{array}{c}\text { Fémur } \\
(\mathrm{mm})\end{array}$} & \multicolumn{2}{c}{$\begin{array}{c}\text { Tibio-fíbula } \\
(\mathrm{mm})\end{array}$} \\
\cline { 3 - 12 } & & Long. & Ancho & Long. & Ancho & Long. & Ancho & Long. & Ancho & Long. & Anchc \\
\hline 1 & 260 & 38.0 & 47.0 & 32.0 & 2.5 & 21.0 & 4.0 & 48.0 & 4.0 & 44.0 & 3.0 \\
2 & 130 & 57.0 & 39.0 & 26.0 & 2.0 & 17.0 & 3.0 & 40.0 & 3.0 & 38.0 & 3.0 \\
3 & 285 & 30.0 & 41.0 & 25.0 & 2.0 & 17.0 & 3.0 & 40.0 & 2.5 & 38.0 & 3.0 \\
4 & 145 & 31.0 & 42.0 & 23.0 & 2.0 & 16.0 & 3.0 & 42.0 & 2.0 & 38.0 & 2.5 \\
5 & 375 & 34.0 & 48.0 & 32.0 & 3.0 & 20.0 & 4.5 & 53.0 & 4.0 & 47.0 & 3.0 \\
6 & 385 & 34.0 & 49.0 & 34.0 & 2.5 & 21.0 & 4.0 & 54.0 & 4.0 & 49.0 & 3.0 \\
\hline Media & 263.3 & 37.33 & 44.33 & 28.67 & 2.33 & 18.67 & 3.58 & 46.17 & 3.25 & 42.0 & 2.92 \\
d.e. & 109.1 & 10.0 & 4.18 & 4.55 & 0.41 & 2.25 & 0.66 & 6.40 & 0.88 & 5.14 & 0.20 \\
\hline
\end{tabular}

Cuadro 2. Medidas de largo y ancho del calcáneo, astrágalo, sacro, cadera, longitud del esqueleto y número de vértebras del esqueleto axial de seis especímenes de la especie Pipa pipa del Parque Zoológico de Huachipa, Lima, determinadas mediante examen radiológico

\begin{tabular}{ccccccccccc}
\hline \multirow{2}{*}{ Rana } & \multicolumn{2}{c}{$\begin{array}{c}\text { Calcáneo } \\
(\mathrm{mm})\end{array}$} & \multicolumn{2}{c}{$\begin{array}{c}\text { Astrágalo } \\
(\mathrm{mm})\end{array}$} & \multicolumn{2}{c}{$\begin{array}{c}\text { Sacro } \\
(\mathrm{mm})\end{array}$} & \multicolumn{2}{c}{$\begin{array}{c}\text { Cadera } \\
(\mathrm{mm})\end{array}$} & $\begin{array}{c}\text { Esqueleto } \\
(\mathrm{mm})\end{array}$ & $\begin{array}{c}\text { Vértebras } \\
(\mathrm{n})\end{array}$ \\
\cline { 2 - 10 } & Long. & ancho & Long. & ancho & Long. & ancho & Long. & ancho & Long. & \\
\hline 1 & 23.0 & 3.5 & 23.0 & 3.0 & 31.0 & 29.0 & 59.0 & 8.5 & 132.0 & 8 \\
2 & 21.0 & 2.0 & 21.0 & 3.0 & 28.0 & 28.0 & 46.0 & 8.0 & 112.0 & 8 \\
3 & 21.0 & 2.0 & 21.0 & 2.0 & 29.0 & 28.0 & 55.0 & 7.0 & 141.0 & 8 \\
4 & 20.0 & 2.0 & 20.0 & 3.0 & 24.0 & 25.0 & 43.0 & 7.0 & 120.0 & 8 \\
5 & 25.0 & 2.0 & 25.0 & 2.0 & 35.0 & 37.0 & 53.0 & 9.0 & 151.0 & 8 \\
6 & 25.0 & 2.0 & 25.0 & 3.0 & 38.0 & 34.0 & 71.0 & 12.0 & 170.0 & 8 \\
\hline Media & 22.50 & 2.26 & 22.50 & 2.67 & 30.83 & 30.17 & 54.50 & 8.58 & 137.67 & 8 \\
d.e. & 2.17 & 0.6 & 2.17 & 0.52 & 5.04 & 4.45 & 9.99 & 1.86 & 21.15 & 0 \\
\hline
\end{tabular}


Cuadro 3. Medidas del largo de tibia-fíbula y del pie, longitud corporal y relación porcentual con la longitud del esqueleto de seis especímenes de la especie Pipa pipa del Parque Zoológico de Huachipa, Lima, determinadas mediante examen radiológico

\begin{tabular}{cccccc}
\hline Rana & $\begin{array}{c}\text { Longitud } \\
\text { tibio-fíbula } \\
(\mathrm{mm})\end{array}$ & $\begin{array}{c}\text { Longitud del } \\
\text { pie } \\
(\mathrm{mm})\end{array}$ & $\begin{array}{c}\text { Longitud } \\
\text { tibio- } \\
\text { fíbula/pie } \\
(\mathrm{mm})\end{array}$ & $\begin{array}{c}\text { Longitud } \\
\text { corporal } \\
(\mathrm{mm})\end{array}$ & $\begin{array}{c}\text { Relación tibio- } \\
\text { fíbula- pie } \\
\text { /argo corporal } \\
(\%)\end{array}$ \\
\hline 1 & 44.0 & 72.0 & 116.0 & 132.0 & 87.88 \\
2 & 38.0 & 64.0 & 102.0 & 112.0 & 91.07 \\
3 & 38.0 & 72.0 & 110.0 & 141.0 & 78.01 \\
4 & 38.0 & 67.0 & 105.0 & 120.0 & 87.50 \\
5 & 47.0 & 77.0 & 124.0 & 151.0 & 82.12 \\
6 & 49.0 & 84.0 & 133.0 & 170.0 & 78.24 \\
\hline Media & 42.3 & 72.7 & 115.0 & 137.7 & 84.1 \\
d.e. & 5.0 & 7.2 & 11.8 & 21.2 & 5.5 \\
\hline
\end{tabular}
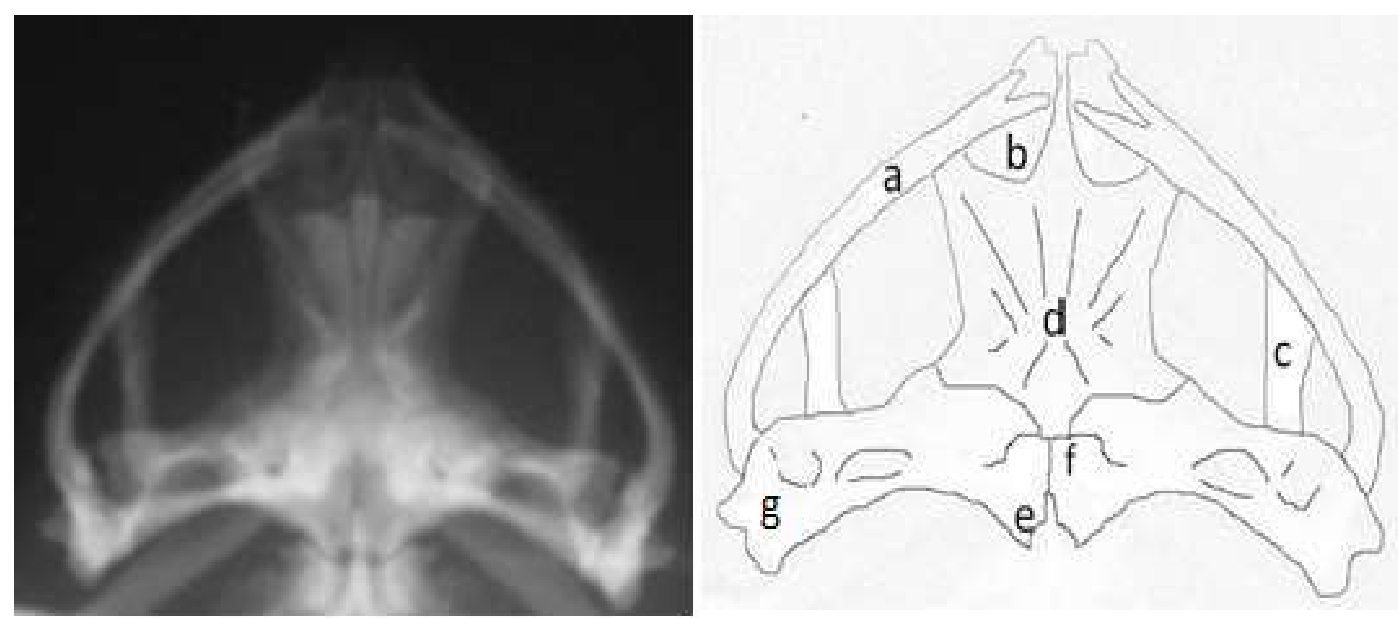

Figura 1. Imagen radiográfica y esquema de los huesos de la cabeza de rana Pipa pipa en seis especímenes del Parque Zoológico Huachipa, Lima. (a) maxilar, (b) nasal, (c) pterigoides, (d) rontoparietal, (e) cóndilo occipital, (f) exoccipital, (g) timpanoescuamosal

Trueb y Cannatella (1986) mencionan que la relación entre las medidas del largo de la tibio-fíbula sumado al largo del pie con el largo corporal corresponde cerca del $90 \%$ de esta última, habiéndose obtenido en este estudio el $85 \%$. La característica de poseer miembros posteriores largos se debe a que requiere impulsarse durante la captura de sus presas, ya que esta especie no tiene lengua a comparación de otras especies de ranas que utilizan la lengua retráctil para la captura (Kardong, 1999).

En referencia a la estructura alargada de radiopacidad intermedia, ubicada entre la III y $\mathrm{V}$ vértebra en 4 de los 6 especímenes, correspondería a la osificación del aparato laríngeo, como se ha descrito en especímenes 

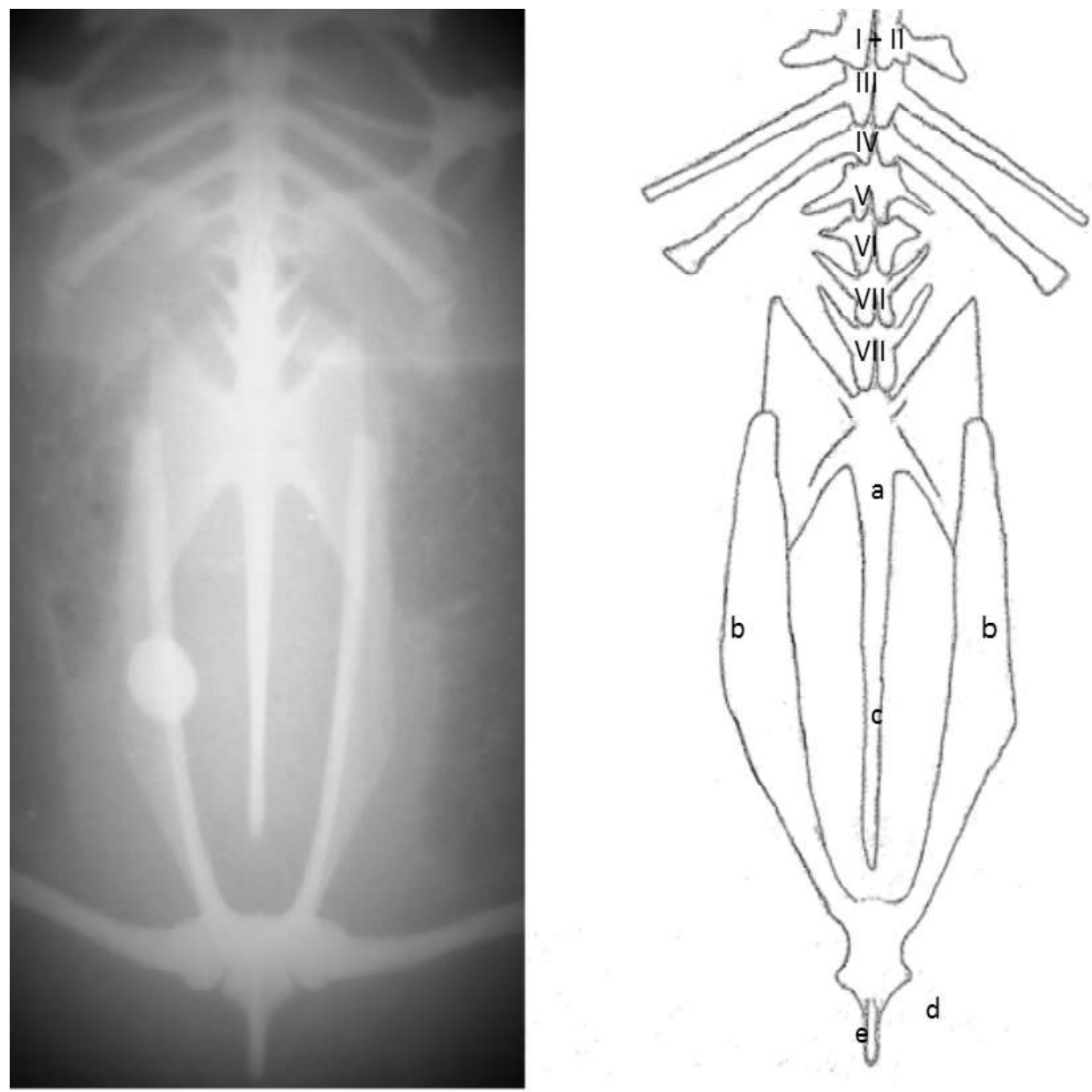

Figura 2. Imagen radiográfica pos-craneal y esquema de los huesos de la rana Pipa pipa en seis especímenes del Parque Zoológico Huachipa, Lima. (I-VII) vértebras, (a) sacro, (b) isquion, (c) urostilo, (d) acetábulo, (e) pubis
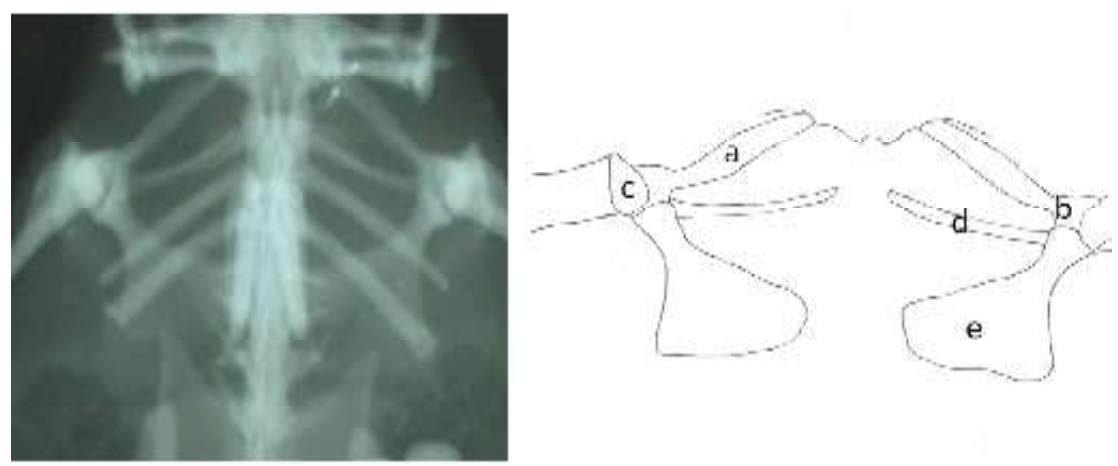

Figura 3. Imagen radiográfica de la cintura escapular y esquema de los huesos de la rana Pipa pipa, en seis especímenes del Parque Zoológico Huachipa, Lima. (a) clavícula, (b) escápula, (c) cleitrum, (d) fosa glenoide, (e) coracoide. Ver detalle de estructura alargada de radiopacidad intermedia ubicada entre la III y V vértebra 

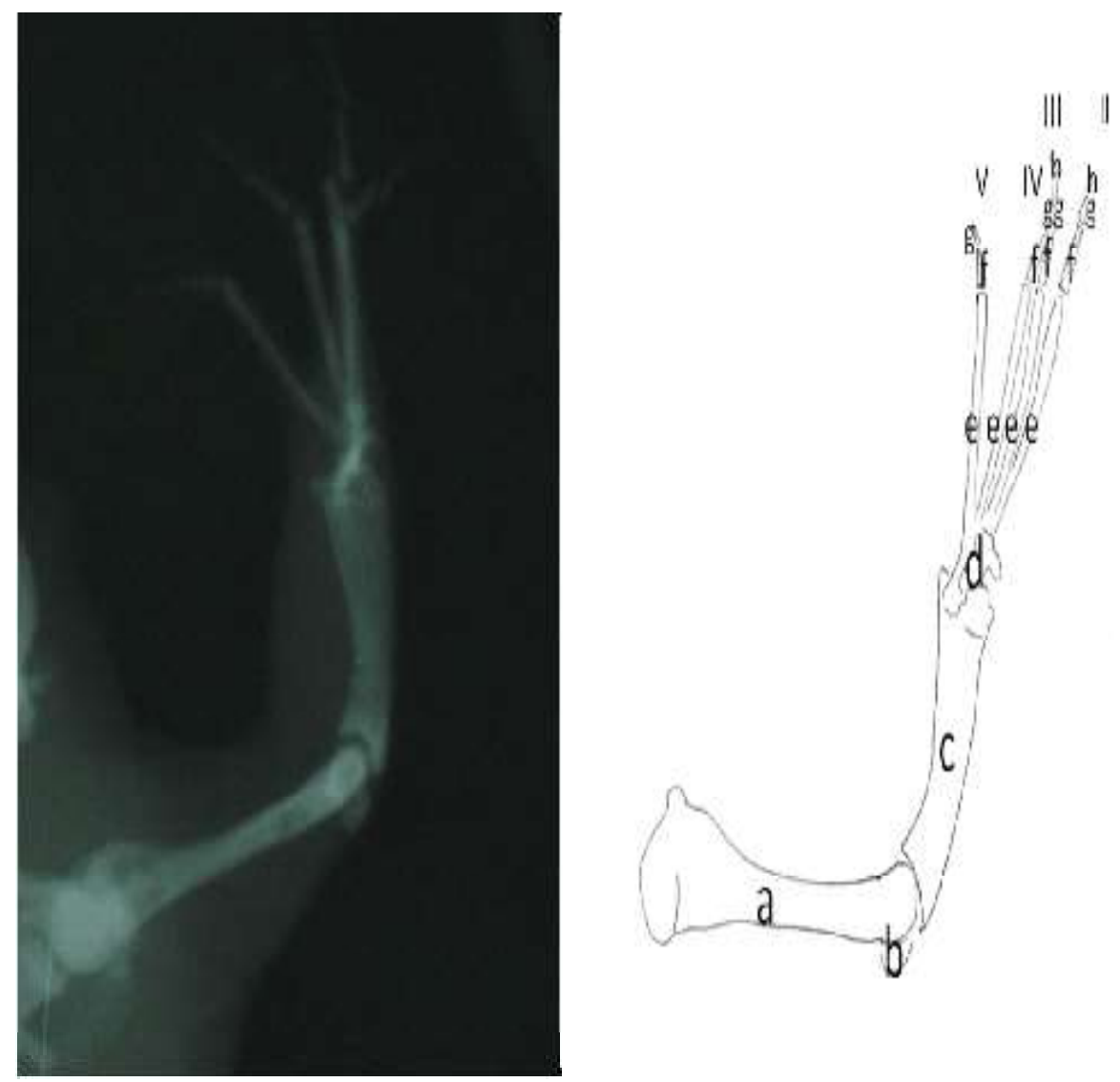

Figura 4. Imagen radiográfica de los huesos del miembro anterior de la rana Pipa pipa y su esquema, en seis especímenes del Parque Zoológico Huachipa, Lima. (a) húmero, (b) sesamoideo, (c) radio-ulna, (d) sesamoideos, (e) metacarpos; (f) falanges proximales, (g) falanges distales, $(\mathrm{h})$ falanges adicionales

machos de esta especie (Trueb et al., 2000), el cual cumple funciones de vocalización, respiración y alimentación (Emerson, 2005). Al respecto, Irisarri et al. (2011) indican que las pipas, al carecer de cuerdas vocales, la laringe se dispone como una caja muy amplia, parcialmente osificada, formada por el cartílago cricoide y los tiroideos, que no forman parte de la laringe de ranas no pipidas, e incluye en su conformación a los cartílagos aritenoides que se modifican y adoptan la forma de dos barras óseas.

El uso de radiología en la descripción osteológica en este estudio tuvo como principal ventaja considerar la interrelación entre los tejidos blandos, articulares y musculares en la disposición de los huesos en su ubica- ción tridimensional en los especímenes evaluados, a diferencia de la técnica convencional con huesos desecados.

\section{ConClusiones}

- Se determinó que esta especie presenta las vértebras pre-sacrales I y II fusionadas y el sacro fusionado al urostilo.

- La cintura escapular es pseudofirmisternal, lográndose identificar los huesos que conforman esta región, incluido el coracoides.

- La relación entre las medidas del largo de la tibio-fíbula sumado al largo del pie con el largo corporal correspondió al 84.1\%. 

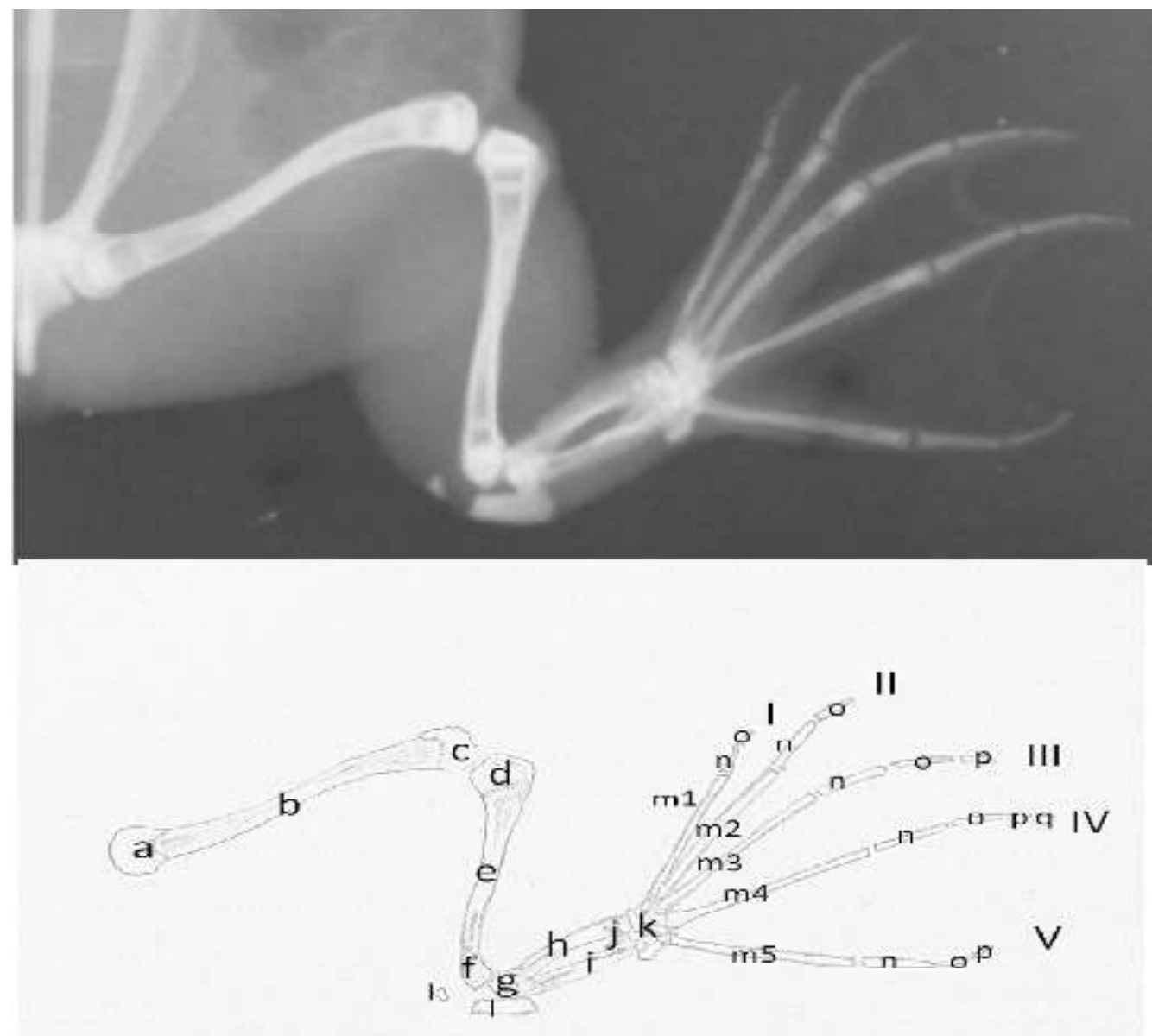

Figura 5. Imagen radiográfica de los huesos del miembro posterior y esquema de rana Pipa pipa en seis especímenes del Parque Zoológico Huachipa, Lima. (a) caputfemoralis, (b) fémur, (c) cabeza distal del fémur, (d) cabeza distal de la tibio-fíbula, (e) tibiofíbula, (f) cabeza distal de la tibio-fíbula, (g) cabeza distal de la unión calcáneo-astrágalo, (h) calcáneo, (i) astrágalo, (j) cabeza distal de la unión calcáneo-astrágalo, (k) elementos tarsales, (1) sesamoideos, (m) metatarsales I-V, (n) falanges proximales, (o) falanges mediales, (p) falanges distales, (q) falange adicional

- Un hallazgo incidental fue la descripción de una estructura alargada de radiopacidad intermedia ubicada entre la III y $\mathrm{V}$ vértebra que correspondió al aparato laríngeo calcificado.

\section{Literatura Citada}

1. [AMNH] American Museum of Natural History. (s.f.) Frog fan facts. New York. [Internet]. Available in: http:/ /www.amnh.org/exhibitions/pastexhibitions/frogs-a-chorus-of-colors/ frog-fun-facts

2. AmphibiaWeb. (s.f.) Information on amphibian biology and conservation. Berkeley, California: [Internet]. Disponible en: http://amphibiaweb.org/

3. Ballard B, Cheek R. 2003. Exotic animal medicine for the veterinary technician. Iowa, USA: State Press. $p$ 171-172. 
4. Báez A, Scanferla C, Agnolin F, Cenizo M, De los Reyes M. 2008. Pipid frog from the pleistocene of the Pampas of Southern South America. Argentina. J Vertebr Paleontol 28: 1195-1198.

5. BáezAM, Trueb L. 1997. Redescription of the paleogene Shelania pascua$l i$ from Patagonia and its bearing on the relationships of fossil and recent pipoid frogs. Scientific Papers, Natural History Museum, University of Kansas. 41 p.

6. Borkhvardt V, Ivashintsova E. 1994. On the position of the epicoracoids in amphian arciferal pectoral girdles. Russian J Herpetol 1: 114-116.

7. Carreño C, Nishikawa K. 2010. Aquatic feeding in pipid frogs: the use of suction for prey capture. J Exp Biol 213: 2001-2008. doi: 10.1242/jeb.043380

8. Emerson S. 1983. Functional analysis of frog pectoral girdles. The epicoracoid cartilages. J Zool 201: 293-308. doi: 10.1111/j.1469-7998.1983.tb04278.x

9. Emerson S. 2005. Movement of the hyoid in frogs during feeding. Am J Anat 149: 115-120. doi: 10.1002/aja.1001490109

10. Fowler M, Cubas Z. 2001. Biology, medicine, and surgery of South American wild animals. USA: Iowa State University Press. 520 p.

11. Irisarri I, Vences M, San Mauro D, Glaw F, Zardoya R 2011. Reversal to air-driven sound production revealed by a molecular phylogeny of tongueless frogs, family Pipidae. Evol Biol 11: 114. doi: 10.1186/1471-2148-11-114

12. [IUCN] International Union for Conservation of Nature and Natural Resources. Pipa pipa. The IUCN Red List of threatened species 2017-3. [Internet]. Available in: http://dx.doi.org/ 10.2305 / I U C N . U K . 2015 4.RLTS.T58163A61414791.en

13. Kardong VK. 1999. Vertebrados: anatomía comparada, función y evolución. España: McGraw-Hill. 896 p.
14. Kaplan M. 1993. An evaluation of the current use of the breast-shoulder apparatus characters in anurans. $\mathrm{PhD}$ Thesis. Nebraska, USA: University of Nebraska. 470 p.

15. Lannoo M. 2008. Malformed frogs. The collapse of aquatic ecosystems. California, USA: University of California Press. 288 p.

16. Miller E, Fowler M. 2012. Fowler's zoo and wild animal medicine. Vol 8. USA: Elsevier. $792 \mathrm{p}$.

17. [MINAN] Ministerio de Ambiente, [AECID] Agencia Española de Cooperación Internacional para el Desarrollo. 2009. Amazonía, guía ilustrada de flora y fauna. Lima: Serigrafica Industrial. $459 \mathrm{p}$.

18. Scherff-Norris K, Livo L, Pessier A, Fetkavich C, Jones M, Kombert M, Goebel A, Spencer B. 2002. Native aquatic species restoration facility. Boreal toad husbandry manual. Colorado, USA: Colorado Division of Wildlife. $78 \mathrm{p}$.

19. Trueb L. 1984. Description of a new species of Pipa (Anura: Pipidae) from Panama. USA. Herpetologica 40: 225234.

20. Trueb L, Cannatella D. 1986. Systematics, morphology, and phylogeny of genus Pipa (Anura: Pipidae). Herpetologica 42: 412-449.

21. Trueb L, Massemin D. 2000. The osteology and relationships of Pipa aspera (Amphibia: Anura: Pipidae), with notes on its natural history in French Guiana. Amphibia Reptilia 22: 33-54. doi: 10.1163/156853801750096169

22. Trueb L, Púgener A, Maglia A. 2000. Ontogeny of the bizarre: an osteological description of Pipa pipa (Anura: Pipidae), with an account of skeletal development in the species. J Morphol 243: 75-104. doi: 10.1002/(SICI)1097$4687(200001) 243: 1<75::$ A ID JMOR4>3.0.CO;2-L 